\title{
A ORIGEM DO PLANO NACIONAL DE EDUCAÇÃO E COMO ELE ABORDOU AS QUESTÕES DE GÊNERO
}

\section{EL ORIGEN DEL PLAN NACIONAL DE EDUCACIÓN Y CÓMO ABORDÓ LAS CUESTIONES DE GÉNERO}

\author{
THE ORIGIN OF THE NATIONAL EDUCATION AND HOW HE \\ STUDIED AS GENDER ISSUES
}

\author{
José Jairo VIEIRA ${ }^{1}$ \\ Carla Chagas RAMALHO ${ }^{2}$ \\ Andréa Lopes da Costa VIEIRA ${ }^{3}$
}

RESUMO: Este trabalho traz a construção histórica do Plano Nacional de Educação, mostra como a realidade político social influenciou e influência a sua formatação ou até, em alguns momentos, impossibilitou-a. Após essa construção histórica, iremos analisar como o tema gênero transcorre, ou não, de forma direta no decorrer dos textos dos respectivos Planos Nacionais de Educação. Esse artigo traz como objetivo o questionamento de até onde a abordagem gênero, é feita no Plano Nacional de Educação que norteia o sistema educacional do país. Por fim faremos algumas conclusões de como um país, como o Brasil, que se encontra na sétima posição relacionada a violência contra mulheres (no ranking mundial), deveria se portar em seus documentos educacionais para incentivar as problematizações sobre identidade de gênero nas escolas e deixar de tornar um assunto tabu, para procurar, efetivamente, reduzir o número de crimes direcionados a mulheres como, também, todas as violências relacionadas a gênero.

PALAVRAS-CHAVES: Políticas públicas de educação. Plano nacional de educação. Gênero.

RESUMEN: Este trabajo trae la construcción histórica del Plan Nacional de educación, muestra cómo la realidad política social influenció e influenció su formateo o incluso, en pocos momentos, lo hizo imposible. Después de esta construcción histórica, examinaremos cómo la cuestión de género es, o no, directamente en el curso de los textos de los respectivos planes educativos nacionales. Este artículo tiene por objeto cuestionar en lo que se refiere al enfoque de género en el Plan Nacional de educación que guía el sistema educativo del país. Finalmente, vamos a hacer algunas conclusiones de cómo un país, como Brasil, que está en la séptima posición relacionada con la violencia contra la mujer (en el ranking mundial), debe comportarse en sus

\footnotetext{
${ }^{1}$ Professor Associado da Faculdade de Educação e do Programa de Pós-Graduação em Educação (PPGE) da UFRJ. E-mail: diversidade.desigualdade.educa@gmail.com

2 Mestre em Educação pela Universidade Federal do Rio de Janeiro. E-mail: diversidade.desigualdade.educa@gmail.com

${ }^{3}$ Professora Associada I no Departamento de Ciências Sociais da Universidade Federal do Estado do Rio de Janeiro (UNIRIO). E-mail: diversidade.desigualdade.educa@gmail.com
} 
documentos educativos para alentar la Problematizações sobre la identidad de género en las escuelas y dejar de hacer un tema tabú, para tratar efectivamente de reducir el número de delitos dirigidos a las mujeres como Además, toda violencia relacionada con el género.

PALABRAS CLAVE: Políticas de educación pública. Plan nacional de educación. Género.

ABSTRACT: This work brings the historical building of the National Education Plan shows how the social and political reality influenced and influence its formatting or even, at times, prevented it. After this historic building, we will analyze how the gender issue takes place or not, directly over the texts of their National Education Plans. This article has as objective the question of how far the genre approach is taken in the National Education Plan that guides the country's education system. Finally we will make some conclusions on how a country like Brazil, which is in the seventh position related to violence against women (in the world), should behave in their educational documents to encourage problematizations on gender identity in schools and let to make a taboo subject, to search effectively reduce the number of crimes directed at women, too, like all violence related to gender.

KEYWORDS: Public education policies. National education plan. Gender.

\section{Introdução}

O presente trabalho relata como a construção histórica do Plano Nacional de Educação (PNE) está relacionada diretamente com o contexto histórico social do Brasil espelhando algumas expectativas da sociedade sobre as instituições escolares, assim como o inverso, as expectativas das escolas com a sociedade.

Tendo esta convicção da relação quase siamesa entre o PNE e a história social, analisamos como as identidades de gêneros são focadas dentro desses Planos, para ter uma compreensão de como as relações de gênero são vistas na nossa sociedade e, por seguinte, na escola, sendo reforçadas, implantadas, reinventadas a todos os momentos neste ambiente.

A intenção deste estudo parte do pressuposto que a categoria gênero é um dos pilares padronizadores mais consistentes da normatização social, tendo em vista que, os padrões de "normalidade", relacionado ao gênero, são cultivados de diferentes formas e em diversos locais, as instituições escolares são um ambiente importante para estruturação, fabricação, incorporação e manutenção da política e conceitos sociais. No 
convívio escolar aprendemos mais que as disciplinas em questão, incorporamos padrões sociais.

Logo, investigar os PNE e sua origem facilitará na compreensão da naturalização e/ou desnaturalização de uma visão heteronormativa ${ }^{4}$ no contexto escolar, pois é importante apontar como e se chegam até essas leis.

O Histórico do Plano Nacional de Educação

As instituições educacionais brasileiras não possuem um sistema nacional único que padronize seus conteúdos e suas avaliações, porém existem tentativas históricas de viabilizar metas e objetivos comuns para a educação no território nacional. Com este intuito, veremos como o PNE surgiu na história da educação brasileira para buscar objetivar e estipular metas equivalentes, assim como estipular investimentos de cada esfera governamental.

Para compreendermos melhor o contexto que o PNE surgiu, é necessário entender a situação histórica do Brasil. A discussão sobre o PNE começou com a Era Vargas, um período marcado pelo nacionalismo, pela forte identidade nacional que Getúlio Vargas queria dar ao Brasil. E, a via principal para preparar a sociedade para ser uma grande nação, era através da educação, através dela acreditava-se que todos os problemas do país (estruturais, financeiros, entre outros) iriam se resolver.

Com o ideal de realizar projetos de leis que culminassem no propósito de uma nação forte através da educação. Criou-se então o Ministério dos Negócios da Educação e Saúde Pública (1930) tendo como titular Francisco Campos, o que já mostrava a intenção de unificar a educação brasileira.

Em seguida, em 1931, houve a Reforma Francisco Campos, sendo criado o Conselho Nacional de Educação (CNE), que trazia como atribuição do CNE a formatação do Plano Nacional de Educação. Sendo assim ratificada a necessidade de começar o diálogo para culminar num conjunto de metas para todo o território nacional, o que se tratando de um país grande e com diversas regionalidades, necessitaria de um amplo diálogo para que de forma legítima abarcasse a todos e todas.

Proponho que o Conselho Nacional de Educação, tendo presente os objetivos patrióticos de sua instituição e fazendo uso das atribuições fundamentais, que lhe confere o decreto n. 19.850, de 11 de abril de 1931, designe uma ou mais comissões para o preparo e a redação de um plano nacional de educação, que deve ser aplicado e executado dentro de um período de tempo, que nele será fixado (Cury, 2011, p.798)

4 O termo heteronormatividade surgiu em 1991 por Michael Warner, que indica como a heterossexualidade é enaltecida a ponto de ser praticamente compulsória na sociedade atual. 
Assim, nessa discussão sobre a unificação da educação brasileira, ficaram marcadas por duas correntes que atribuíam seus ideais a educação que transcorreriam para um modelo de nação, pois segundo as duas abordagens a educação seria a constituição primordial para uma modificação nacional. Essas duas vertentes eram distinguidas em: pioneiros da educação (conhecidos também como pertencentes da Escola Nova $)^{5}$ e representantes da igreja católica ${ }^{6}$.

Os representantes da escola nova traziam uma nova forma de aplicação e de visão da prática escolar, viam a potencialidade de um ensino diferenciado, onde o aluno não apenas reproduzia mais descobria o conhecimento através de experiências, visando à formação de cidadãos críticos de um país com novas perspectivas, o objetivo deste grupo eram escolas democráticas e que incentivassem a formação humana e crítica dos alunos e alunas.

Os representantes da igreja católica queriam manter a força da igreja católica como religião já influenciando o direcionamento das escolas brasileiras. Para isso se embasavam em um ensino dito tradicional onde o professor era o detentor principal do saber e os alunos e alunas absorviam, apenas, o ensinamento. Com os representantes da igreja católica tendo voz ativa num Plano Nacional de Educação, acabaria por fortalecer a religião católica no país.

E, no decorrer desta discussão sobre a formatação do primeiro Plano Nacional de Educação (PNE), em 1934 a constituição brasileira é modificada e traz referencia direta ao PNE. Em seu artigo 150, deixa claro que compete a união "fixar o plano nacional de educação, compreensivo do ensino de todos os graus e ramos, comuns e especializados; e coordenar e fiscalizar a sua execução, em todo o território do País;". Como também, no artigo 152, a constituição designava a atribuição da elaboração do PNE ao CNE, ou seja, após as reuniões e os debates de ideias provindas do CNE surgiria o PNE pronto para a implementação.

Com esta definição constitucional o direcionamento legal da construção e aplicação do PNE foi se tornando cada vez mais robusto, porém, sua aplicabilidade ainda não era discutida efetivamente, todas as considerações eram traçadas de maneira

5 Constituída por algumas pessoas como Fernando de Azevedo, Anísio Teixeira, Afrânio Peixoto, Lourenço Filho, Antônio F. Almeida Junior, Roquette Pinto, Delgado de Carvalho, Hermes Lima e Cecília Meireles

6 “Mobilizado por D. Sebastião Leme e engajado em sua proposta de recristianização do país, um grupo de católico - formão por intelectuais, políticos, diplomatas - impunha-se o dever de defender a religião católica a qualquer custo" (SHIROMA, 2007, P.17) 
teórica sem efetivamente pensar na sua aplicação prática, como se a escrita legal sanasse todos os problemas.

Parecia ao governo que, uma vez equacionados no âmbito da legislação, os problemas educacionais encontrariam solução real, como decorrência natural da lei bem formulada. (Shiroma, 2007, p.17)

Após percorrer os tramites que haviam sidos designados para a construção do mesmo, e após muita discussão das correntes por espaços reais no projeto final do PNE, a proposta foi levada para a votação na câmara em 1937, tendo um parecer positivo para a aprovação do mesmo pelo relator da câmara. Porém, no final do mesmo ano ocorreu um golpe político, dando início a era do Estado Novo, fazendo com que todos os poderes representativos (incluindo a câmara, onde o PNE se encontrava) fosse fechado.

Logo, este projeto fica engavetado, e, não só ele, mas o ideal de uma educação diferenciada para uma nação democrática também. Pois, logo após o Estado Novo veio o governo de Gaspar Dutra (1946 - 1951) com uma corrente mais liberal onde o foco da educação direcionava para atrativos do mercado de trabalho ao invés da formação humana. Mas, mesmo com outro enfoque, o objetivo de retornar a discussão de uma educação com as mesmas diretrizes em âmbito nacional retornaram, como podemos ver na constituição do ano de 1946 em seu artigo quinto: "Compete à União: XV - legislar sobre: d) diretrizes e bases da educação nacional;". Mas, de forma efetiva, não houve nenhuma contribuição para a formatação e aplicação do primeiro PNE.

Somente no governo de João Goulart (1956-1964), que tivemos mais desdobramentos específicos sobre o PNE, onde foi direcionado, através da lei número 4.024, de 20 de dezembro de 1961, a retomada da atribuição do CNE em discutir e formatar o PNE. E foi um ano após, em 1962 que surgiu o primeiro PNE brasileiro, mas este documento não surgiu como um projeto de lei, e sim como um conjunto de regras que visava algumas aplicações financeiras, "[...] era basicamente um conjunto de metas quantitativas e qualitativas a serem alcançadas num prazo de oito anos.” (Brasil, 2000, p.6).

E nos anos seguintes pouco, para não dizer quase nada, se progrediu na direção de uma educação crítica e democrática, pois em 1964 começava os anos da ditadura civil militar, onde a educação privada teve um aumento peculiar e a educação pública ia cada vez mais se desvalorizando. O PNE no ano de 1964 foi modificado, “[...] quando foram introduzidas normas descentralizadoras e estimuladoras da elaboração de planos 
estaduais" (Brasil, 2000, p.6), regredindo, após apenas dois anos da sua implementação, de um plano nacional, para vários planos regionais, tirando a responsabilidade federal, minimizando, com isso, os deveres financeiros da mesma.

Retrato da falta da obrigatoriedade legal de investimento na educação pública pode ser observado na constituição de 1967 ,

A Constituição de 24 de janeiro de 1967, baixada pelo regime militar, eliminou a vinculação orçamentária constante das Constituições de 1934 e de 1946, que obrigava a União, os estados e os municípios a destinar um percentual mínimo de recursos para a educação (Saviani, 2008, p. 298).

Já neste período de ditadura civil militar, a hipervalorização das políticas de mercado dentro do campo educacional já era mais incisiva, como Saviani (2008) aponta, não só em facilitar a abertura de escolas privadas, mas também aumento o incentivo à mentalidade privatista nas escolas públicas.

Com o PNE sem força, sem comprometimentos financeiros efetivos na educação, o objetivo de uma estrutura escolar com objetivos nacionais únicos com metas democráticas e humanizadoras, como havia sido o apontado há décadas atrás, já não era mais sua principal vertente, nem se quer tangenciava esse ideal.

No decorrer da década de 1980 a ditadura civil militar foi perdendo sua força, porém, deixando suas marcas em toda a sociedade, e também na educação. Dessa forma, mesmo após seu fim, a estrutura educacional mantinha uma identidade envolta diretamente com o setor econômico, o que a relacionava com sua dependência financeira internacional.

\footnotetext{
Nessas condições, não é difícil entender os constantes apelos para um maior estreitamento dos vínculos entre educação e mercado, a valorização da iniciativa privada com a consequente ênfase na adoção de mecanismos empresariais na gestão do ensino, assim como as pressões sobre a pós-graduação guiadas pela exigência de produtividade. (Saviani, 2008, p.311)
}

Neste contexto, retornamos o debate sobre a unificação de metas e objetivos para a educação nacional, surgindo assim o a Lei de Diretrizes e Bases (LDB) em 1996, que reaproxima a lei do investimento educacional público como também a necessidade da elaboração do PNE, em seu artigo nove, deixa claro essa obrigatoriedade: “Art. $9^{\circ}$ A 
União incumbir-se-á de: I - elaborar o Plano Nacional de Educação, em colaboração com os Estados, o Distrito Federal e os Municípios;"

Já em seu segundo mandato, o presidente Fernando Henrique Cardoso (FHC) estava cada vez mais estreitando relações com investidores financeiros internacionais e dificultando um diálogo com diferentes correntes sociais. Com este cenário, foi elaborado o PNE conhecido como "Plano Nacional de Educação - A Proposta da Sociedade Brasileira", que se define como:

\begin{abstract}
Este Plano Nacional de Educação é um documento referência que contempla dimensões e problemas sociais, culturais, políticos e educacionais brasileiro, embasado nas lutas e proposições daqueles que defendem uma sociedade mais justa e igualitária e por decorrência uma educação pública gratuita, democrática, laica e de qualidade, para todos, em todos os níveis. Assim, princípios, diretrizes, prioridades metas e estratégias de ação contidas neste Plano consideram tanto as questões estruturais como as conjecturais, definindo objetivos de longo, médio e curto prazos a serem assumidos pelo conjunto da sociedade enquanto referenciais claros de atuação. (CONSED, 1997, p.2)
\end{abstract}

Este PNE - Proposta da sociedade brasileira, foi escrito com ideais voltados para uma vertente distinta da vigente no governo, foi realizada após discussões e debates num congresso onde tinham representantes de sindicatos e de vários setores da sociedade, ou seja, com interesses políticos e educacionais bem diferentes do que o governo FHC trazia, por isso não teve grande expressividade nacional, mas vale a pena ser relatado como ponto de resistência.

O governo FHC, no ano posterior (1998), efetivamente começa a discussão sobre o PNE que compactuava, com a hegemonia política que norteava seu governo, o que incluía um mundo globalizado e uma política neoliberal. Assim,

Somente no início de 2001 foi aprovado o Plano Nacional da Educação - PNE pela Lei ${ }^{\circ} 10.172$ de 10/01/2001, com vários vetos, em especial, a emenda que propunha o investimento de $10 \%$ do Produto Interno Bruto em educação. (Bonamigo et al, 2011, p.2)

A característica principal deste PNE implementado, era a aceitação das exigências feitas por órgãos e empresas estrangeiras financiadoras no país para continuar com seus investimentos, como por exemplo, a redução do analfabetismo ou, mais claramente, o aumento da educação profissional e "Estabelecer parcerias entre os 
sistemas federal, estaduais e municipais e a iniciativa privada, para ampliar e incentivar a oferta de educação profissional. " (PNE, 2001)

Dessa forma, tivemos constituídos o segundo PNE brasileiro, que em seu caput deixava definido seu período de aplicação de dez anos, ou seja, no prazo de 2001 até 2011. Abrindo assim, um precedente para a modificação do prazo de sua aplicação que havia ficado imprecisa na constituição de 1988 com o termo: "plurianual". Esta definição pode ter favorecido a aplicação da Emenda Constitucional n. 59/09, que trazia em seu texto

Art. 214. A lei estabelecerá o plano nacional de educação, de duração decenal, com o objetivo de articular o sistema nacional de educação em regime de colaboração e definir diretrizes, objetivos, metas e estratégias de implementação para assegurar a manutenção e desenvolvimento do ensino em seus diversos níveis, etapas e modalidades por meio de ações integradas dos poderes públicos das diferentes esferas federativas que conduzam a: (Emenda Constitucional n. 59/09)

Transcorrido os anos de aplicação para o PNE de 2001, começaram os estudos, através do CNE para a formatação de um novo PNE, porém, teríamos um contexto político econômico teoricamente distinto da década anterior quando foi escrito o, até então, último PNE. O presidente do país era Luis Inácio Lula da Silva, um presidente com raízes sindicais e que fora eleito com expectativas de modificações nas desigualdades sociais que o sistema econômico globalizado vinha impondo ao Brasil.

Porém, o governo apenas foi reforçando algumas diretrizes deixadas pelo governo anterior, mantendo uma negociação aberta com o mercado exterior. Assim, o novo PNE de 2011 aparece de forma mais concisa, e com o diferencial de apontar estratégias e metas mais diretas nos objetivos almejados. Mas, fica claro que o governo brasileiro torna-se cada vez mais conivente com o pensamento e ações onde o importante é agradar e satisfazer os empreendedores estrangeiros, e não os cidadãos brasileiros. Tornando a escola unitária (LEHER, 2010), pública e de qualidade para todos e todas cada vez mais distante da realidade dos brasileiros e das brasileiras.

\section{O Plano Nacional de Educação e sua abordagem sobre as questões de gêneros}

Quando falamos sobre questões de gênero e PNE é importante ressaltar a relevância que o tema gênero tem no ambiente escolar. Compreendendo a escola como um ambiente onde há disseminação de ideais sociais de várias formas, explícitas ou 
implícitas, trazemos para a discussão Guacira Louro (2011), que mostra como o paradigma gênero é reforçado, ensinado e reinventado dentro da escola. A autora busca questionar as expressões de gêneros e sexualidade impostas, mesmo de forma subjetiva, pelas escolas. "É indispensável que reconheçamos que a escola não apenas reproduz ou reflete as concepções de gênero e sexualidade que circulam a sociedade, mas que ela própria a produz." (ibdem, p.84)

Entendendo que o gênero é um pilar norteador importante para a sociedade, e sabendo que o ambiente escolar, por lei, é um espaço onde todos os cidadãos e cidadãs deveriam passar ao menos nove anos de suas vidas, seria um local propício para haver questionamentos que balizassem conceituações sobre gêneros e que podem vir a refletir numa sociedade mais justa. Por isso, analisar o PNE, o que ele traz sobre o tema, é importante para podermos questionar a obrigatoriedade das professoras e professores neste contexto, como os demais atores envolvidos no ambiente escolar.

Com este olhar crítico e com a autora Louro, iremos analisar os PNEs que já vigoraram e o que está em vigor em âmbito nacional para buscar explorar seus conteúdos de forma direta, através da forma que é exposto nas metas e diretrizes destes planos.

\section{PNE 1962}

Este PNE foi direcionado mais para as questões logísticas da aplicação do processo educacional, não chega a identificar qual ideário educação, especificamente, seria o objetivo ou gostaria de se chegar através deste Plano de Educação. O que torna difícil analisar, especificamente, o conteúdo sobre gênero. Logo, podemos fazer poucas considerações diretas e algumas observações, sem grandes pretensões, subjetivas.

$\mathrm{O}$ documento traz todas as nomenclaturas voltadas para o sexo masculino, o que não está errado, gramaticalmente falando, porém reforça uma valorização masculina e auxilia a trazer as mulheres para o campo da invisibilidade da escrita, o que pode vir a reforçar a invisibilidade nas ações, no trabalho e, por conseguinte, deixando seu trabalho (como professora, diretora, estudante, etc.) cair em demérito.

Outra análise que podemos nos arriscar a fazer é sobre justamente a falta de direcionamento específico sobre o tema, pois se outras temáticas são conceituadas como importantes e fazem parte do PNE, demonstra como as questões de gêneros não eram 
vistas como um fator que merecia tal importância e sequer deveriam ser citados num plano nacional.

\section{PNE - Proposta da sociedade brasileira}

Este Plano é um grande diferenciador entre todos os que foram propostos e efetivados, foi feito através de uma proposta de igualdade de oportunidade, de uma educação que ensinava para libertar, foi baseado nos ideais de política conhecido como de esquerda. O termo igualdade surge sem distorções políticas. O que isso pode influenciar na forma de analisar as questões de gênero? As identidades de gênero transpassam a forma de política e econômica vigente na sociedade, o que significa que não seria só a mudança de um sistema econômico que acabaria com as discriminações de gênero.

Mas, teoricamente, se almejamos uma sociedade onde as desigualdades são disseminadas reduziríamos, por conseqüência, as demais discriminações. Pois, as opressões de gênero podem vir a servir "como uma luva" para fortalecer a prática da coerção e hierarquização na sociedade capitalista. Mas a vida social não é uma ciência exata, e, a origem dos preconceitos e estigmas relacionados às diferentes formas de expressão de gênero, sexualidade ou qualquer outra característica que fuja de um padrão estabelecido, ocorre independente de qual sistema político econômico esteja em vigor na sociedade.

Assim, podemos observar que a escrita deste documento já é diferenciada, já neste momento mostrando a possibilidade de utilizar, de forma igual, expressões femininas e masculinas, o que mostra uma representatividade de ambos. No decorrer do documento fica exposto como a igualdade de gênero não é o ponto principal a ser alcançado, mas sim mais um ponto dentro do conjunto de igualdades almejado pela sociedade.

Permeando a educação brasileira, em todos os seus níveis e modalidades, registram-se, também, as conseqüências sociais do fenômeno da dupla, por vezes tripla, exclusão, quando ao viés sócio-econômico se soma e integra o viés de raça e/ou gênero: além de pobre, ser mulher, negra ou indígena, significa, como regra, estar à margem dos produtos e benefícios socialmente produzidos. 
Dessa forma, este Plano traz considerações importantes que ainda hoje não foram retratadas pelos PNE apresentados pelos governos. E, como foi visto, a categoria gênero acaba servindo para aumentar algumas desigualdades e segmentar, em algumas situações alguns já excluídos ou excluídas.

\section{PNE 2001}

Este PNE é o plano mais completo, apresentado pelo governo, onde há uma contextualização sobre a educação no Brasil e os diferentes setores de sua aplicação.

A sua observação sobre as questões de gênero começa no apontamento sobre o quantitativo de crianças matriculadas na educação infantil, o documento divide por gênero procurando uma igualdade quantitativa, o que foi confirmada como o texto diz:

A distribuição das matrículas, quanto ao gênero, está equilibrada: feminino, $49,5 \%$ e masculino, 50,5\%. Esse equilíbrio é uniforme em todas as regiões do País. Diferentemente de outros países e até de preocupações internacionais, em nosso País essa questão não requer correções.

Este apontamento já mostra uma igualdade de gênero almejada, ao menos de forma mais direta, de maneira quantitativa. Porém mais nenhum questionamento ou discussão específico sobre gênero é falado no texto de Educação Infantil e nem ao menos qual definição de gênero o texto se refere, o que demonstra um trato raso ainda sobre o tema.

Quando começa a tratar sobre o ensino fundamental, passa a ser mais específico, dentro de seus objetivos e metas, sobre a forma que deseja trabalhar com o gênero dentro do ambiente escolar:

11. Manter e consolidar o programa de avaliação do livro didático criado pelo Ministério de Educação, estabelecendo entre seus critérios a adequada abordagem das questões de gênero e etnia e a eliminação de textos discriminatórios ou que reproduzam estereótipos acerca do papel da mulher, do negro e do índio.* 
Trabalhando com a já sabida discriminação social que há socialmente sobre gênero e reconhecendo o papel social da escola em questionar e problematizar esses paradigmas. O que anteriormente, no PNE não havia nem sido retratado, neste já é apontado o problema e visto que deve ter uma problematização sobre.

Após esse apontamento, encontramos outra citação na parte do ensino superior quando fala sobre formação docente:

12. Incluir nas diretrizes curriculares dos cursos de formação de docentes temas relacionados às problemáticas tratadas nos temas transversais, especialmente no que se refere à abordagem tais como: gênero, educação sexual, ética (justiça, diálogo, respeito mútuo, solidariedade e tolerância), pluralidade cultural, meio ambiente, saúde e temas locais.

Mostrando que os professores e as professoras devem tratar sobre o tema durante sua formação para estarem aptos e aptas para falar sobre com seus alunos e alunas.

Nos objetivos e metas da Educação a distância e tecnologias educacionais as questões de gênero aparecem da seguinte forma:

7. Promover imagens não estereotipadas de homens e mulheres na Televisão Educativa, incorporando em sua programação temas que afirmem pela igualdade de direitos entre homens $e$ mulheres, assim como a adequada abordagem de temas referentes à etnia e portadores de necessidades especiais.*

Ressaltando mais uma vez a importância dada no tratamento igualitário que deve ser dado aos homens e mulheres, as questões de gênero no contexto escolar.

\section{PNE 2011}

Este PNE traz uma escrita resumida e sucinta, procura economizar palavras e comprometimentos, em todos os temas, e com gênero não seria diferente.

Este documento começa com suas diretrizes primárias, que embasa todo o plano, e neste início vemos:

$X$ - difusão dos princípios da equidade, do respeito à diversidade e a gestão democrática da educação. 
O que abre possibilidades para relacionarmos com diferentes tipos de diversidades, inclusive com as relacionadas a gênero, porém, nada que deixe claro que é sobre este tema que o PNE esteja se direcionando.

Depois deste apontamento, a meta três remete a importância em universalizar o atendimento escolar para toda a população de 15 a 17 anos, e, dentro das estratégias dessa meta define:

3.9) Implementar políticas de prevenção à evasão motivada por preconceito e discriminação à orientação sexual ou à identidade de gênero, criando rede de proteção contra formas associadas de exclusão.

Nesta citação sobre o preconceito e discriminação relativa à identidade de gênero, mostra que este pode ser um fator que impossibilita a evasão da escola deste aluno neste nível de ensino, nesta fase da vida. Mas, não relata este preconceito em nenhum outro nível de aprendizado da escola, será que esta exclusão escolar, pelo motivo de preconceito de gênero, só ocorre na fase da adolescência do aluno e da aluna?

\section{Análises dos PNEs}

Quando analisamos a origem dos PNE compreendemos como a política majoritária do país serve para fortalecer suas prioridades, com este pensamento os três PNEs, que chegaram a entrar em vigor no Brasil, trouxeram marcas claras dos seus governos. O PNE de 1962 se preocupava mais em especificar questões orçamentárias e deixar em seu texto brechas para, cada vez mais, a educação particular tomar espaço no contexto social. O que resultou num PNE mais preocupado com números do que como e qual educação seria disseminada, qual seria a identidade da educação brasileira.

O segundo PNE já surgiu num contexto político diferente, onde o neoliberalismo mostrava uma de suas características, a manipulação, a pseudo democracia. O que enxergamos no PNE, onde os termos "igualdade", "democracia", entre outros, surgem, mas na totalidade do documento lê-se uma segmentação entre iniciativa privada e pública, uma valorização grande na educação profissional, tendo em vista não o bom 
rendimento dos cidadãos, mas sim a o investimento de instituições internacionais no dito país do futuro.

E, seguindo esses padrões, as questões de gênero aparecem de forma muito bem escrita e direta neste documento, relatam uma nação ideal, sem discriminação de gênero. Para isso narra o fim das discriminações de gênero nos livros didáticos, o que demonstra, teoricamente, o zelo que o governo denota.

Como relata a importância de trazer a tona o assunto para os cursos de licenciaturas para já preparar o futuro professor e a futura professora a trabalhar com a temática, esta preocupação salienta como o preparo em saber como falar sobre o tema é importante, pois, o(a) professor(a), querendo ou não, falando de forma direta ou não, irá transmitir o que acredita ou não, através de seus olhares, roupas, palavras, etc. E o educador e educadora ter consciência de seu papel formador para a criança é fundamental para quem pensa em construir uma sociedade onde haja igualdade real de gênero.

As marcas mais permanentes que atribuímos às escolas não se referem aos conteúdos programáticos que elas possam nos ter apresentado, mas sim se referem a situações do dia-dia, a experiências comuns ou extraordinárias que vivemos no seu interior, com colegas, com professoras e professores. As marcas que nos fazem lembrar, ainda hoje, dessas instituições têm a ver com as formas como construímos nossas identidades sociais, especialmente nossa identidade de gênero e sexual. (Louro, 1999, p.19)

Mas, citar a importância dessa discussão durante a graduação sem apontar de qual forma e quem estaria apto ou apta para ministrar essas aulas, pode se transformar em um efeito contrário ao da igualdade, pode fortificar a segmentação de gênero, embasando alguns preconceitos sociais que, muitas vezes, são tão naturais que chegam a ser quase inquestionáveis.

Neste PNE, a última vez que aparece um apontamento sobre gênero é na Educação a distância, quando reforça o objetivo que anteriormente apareceu que é evitar a discriminação de gênero (entre outras) nos vídeos e matérias utilizados para o aprendizado. Esta análise mostra como a naturalização pode ser feita de forma singela, através de padronizações de figuras de livros, ou histórias que podem ser machistas, ou ainda falta de histórias que mostrem outras formas de culturas e expressões de gênero, $o$ que inviabilizaria o conhecimento do(a) estudante das distintas possibilidades de expressão acerca do gênero. 
No terceiro e vigente PNE, o grupo político que estava no governo mudou, o que refletiu numa formatação do PNE diferente. As políticas neoliberais continuaram a nortear seus objetivos, mas, dessa vez, sem tantas palavras que poderiam colocar em dúvida, ao passar dos dez anos, a credibilidade do documento, como por exemplo: "diminuir a discriminação" neste plano não existe. Existem palavras mais abrangentes e que aparecem em lugares genéricos.

Quando no documento aparece "difusão dos princípios da equidade, do respeito à diversidade e a gestão democrática da educação." Fica claro que esse movimento de difundir é um tanto quanto difícil de metrificar, até por que, ninguém pesquisou seu ponto de partida, logo, qualquer informação que colete no final pode ser encarado como uma difusão da equidade, pois não há parâmetro para nortear.

E da mesma forma abrangente, aparece novamente o tema "gênero", o PNE já vem com a solução para exclusão que ocorre no ensino médio pela discriminação de identidade de gênero, mas, não relata nenhum trabalho anterior a essa fase (no ensino fundamental ou educação infantil) que possa servir de preparo, para evitar chegar nessa situação "estanque" onde o problema já está instalado. E, mesmo o PNE sugerindo políticas públicas para evitar a exclusão desses alunos e alunas que sofrem discriminação, se torna remoto achar que uma política de prevenção (como o nome já diz, que deveria prevenir) fará grande efeito num período curto de três anos, para quem sofre o preconceito, como para quem já possui o hábito de praticá-lo.

\section{Considerações}

É considerável ter as inquietações educacionais relacionadas às identidades de gênero apontadas nos PNEs, já é a demonstração do avanço sobre o tema na sociedade. Levando em consideração que existe uma emergência social em trabalhar com assuntos discriminatórios nas escolas, pois de acordo com dados internacionais de violências contra as mulheres, disponíveis no "Mapa da Violência 2012. Atualização: Homicídio de Mulheres no Brasil", o Brasil ocupa o $7^{\circ}$ lugar, o que demonstra que é necessária uma discussão sobre padronizações relacionadas a gênero na nossa sociedade, urgente, dentro das salas de aula, para questionarmos estigmas e, ao menos, reduzirmos esse quantitativo de violências. 
Todo avanço já é bem vindo, mas temos que ter a pretensão de almejar objetivos maiores e mais profundos, pois as marcas de uma sociedade machista são profundas e estão sendo sempre reforçados, nas propagandas comerciais, nas piadas, nas reportagens, nos comentários das ruas, nas danças, enfim, em todos os lugares temos atores sociais (ou nós mesmos somos) que trata de hierarquizar mais as diferenças de gênero "Homens e mulheres são classificados pelo gênero e separados em duas categorias: uma dominante, outra dominada, obedecendo aos requisitos impostos pela heterossexualidade" (Saffioti, 1995, p.23)

Apenas os atores envolvidos(as) no ambiente escolar, podem modificar algo neste espaço e por conseguinte trazer essa modificação para seu dia-dia, para a sociedade. Mas para haver essa conscientização deve haver a problematização, a dúvida, para tirar a identidade de gênero do "campo" do natural antes de começar a falar sobre, mas para isso deve ter um preparo real e responsável das pessoas envolvidas neste trabalho de conhecimento.

Assim, com o PNE sendo direto e dando a devida importância ao tema "gênero", facilita a entrada do assunto no contexto escolar, pois alguns/algumas professores/as se verão obrigados/as a falar sobre o tema, e dessa forma as problematizações não poderão ser cerceadas como, às vezes, é dentro da escola, o que já é um início para começarmos a mover o grande moinho.

\section{Referências}

BONAMIGO ET AL, História da educação básica brasileria: uma avaliação do plano nacional de educação 2001-2010. IX ANPED-Sul. Seminário de Pesquisa em Educação da Região Sul. 2012

BRASIL. Plano Nacional de Educação, 2000. Disponível em: <http://portal.mec.gov.br/arquivos/pdf/pne.pdf>. Acesso em: 17 jan. 2014.

BRASIL. Lei n. ${ }^{\circ}$ 9.394. de 20 de dezembro de 1996. Estabelece as diretrizes e bases da educação nacional. Disponível em: <http://www.planalto.gov.br/ccivil_03/Leis/L9394.htm>. Acesso em: 17 jan. 2014.

CONSELHO NACIONAL DE EDUCAÇÃO. Plano Nacional de educação: proposta da sociedade brasileira. 1997.

CURY, Carlos Roberto Jamil. Por um novo Plano Nacional de Educação. Cadernos de Pesquisa. São Paulo, vol. 41, n. 144, p. 790-811, set./dez. 2011 
LEHER, Roberto. 25 anos de Educação Publica no Brasil: notas para um balanço do período. In: GUIMARÃES, Catia.; BRASIL, Isabel.; MOROSINI, Márcia. Trabalho, Educação e Saúde: 25 anos de formação Politécnica no SUS. Rio de Janeiro: EPSJV(Fiocruz), 2010

LOURO, Guacira. (Org.). O corpo educado: pedagogias da sexualidade. Belo Horizonte: Autêntica, 1999.

LOURO, Guacira. Gênero, sexualidade e educação: uma perspectiva pósestruturalista. Petrópolis: Vozes, 2011.

SAFFIOTI, Heleieth I. B. Violência de gênero: poder e impotência. Rio de Janeiro: Revinter, 1995.

SAVIANI, Demerval. (2008). O legado educacional do regime militar. Cad. Cedes, Campinas, vol. 28, n. 76, p. 291-312, set./dez.

SHIROMA, E.; MORAES, M.; EVANGELISTA, O. Política educacional. Rio de Janeiro. Lamparina, 2007.

WAISELFISZ, J. J. Mapa da Violência 2012. Atualização: homicídio de mulheres no Brasil. Rio de Janeiro. Cebela/Flacso. 2012

\section{Como referenciar este artigo}

VIEIRA, José Jairo.; RAMALHO, Carla Chagas.; VIEIRA, Andréa Lopes da Costa. A origem do plano nacional de educação e como ele abordou as questões de gênero. Revista on line de Política e Gestão Educacional, Araraquara, v.21, n.1, p. 64-80, 2017. Disponível em: <http://dx.doi.org/10.22633/rpge.v21.n1.2017.9746>. ISSN: 1519-9029.

Submetido em: 21/03/2017

Aprovado em: 30/03/2017 